\title{
Physiological responses to slimming
}

\author{
BY ANDREW M. PRENTICE, GAIL R. GOLDBERG,
} SUSAN A. JEBB, ALISON E. BLACK

AND PETER R. MURGATROYD

$M R C$ Dunn Clinical Nutrition Centre, 100 Tennis Court Road, Cambridge CB2 1QL

\author{
AND ERIK O. DIAZ \\ Instituto Nutricional Central America y Panama, Apartado Postale 1188, Guatemala Ciudad, \\ Guatemala, Central America
}

Overweight people who wish to lose weight are faced with the problem that their metabolism has become accustomed to their state of fatness, indeed it is possible to argue that for them it is their normal state, and when an attempt is made to change it the body displays a number of physiological responses which are designed to protect the status quo. A fuller understanding of these changes will assist nutritionists in devising more successful weight-loss strategies and long-term treatments.

The creation of a negative energy balance, which is necessary for all slimming regimens, invokes a wide variety of different physiological outcomes each of which is likely to be affected by a number of influencing variables. The outcomes include: energy-sparing adaptations, alterations in fat and lean body mass, altered energy substrate handling, changes in appetite, health-related outcomes (e.g. fitness, glucose tolerance), altered hormonal status, and altered fertility. The influencing variables include: genotype, degree of obesity at the onset of slimming, rate and duration of weight loss, the composition of the slimming diet, the incorporation or otherwise of exercise into the slimming regimen, and pharmacological agents if used.

An attempt to cover all the permutations created by this variety of physiological responses and influencing factors would inevitably have to be trivially superficial. In order to avoid this the present review will only consider energy-sparing adaptations and the composition of weight loss. These are two of the most important outcomes and are covered by a substantial body of literature from which some definite conclusions can be drawn.

Before addressing these issues it is worth recapitulating on the intended functions of adipose tissue. Although other functions have been suggested, including insulation and sexual signalling, we assume that the primary function is as an energy reserve to be called upon when food supplies are precarious and when food shortages occur; a situation still common in many areas of the world. Studies at our field-station in Keneba, The Gambia, have documented profound seasonal weight changes in adults which are caused by an annual hungry season when the previous year's food supplies start to run out (Prentice et al. 1981). At the height of the Sahelian drought years women were losing and regaining about $50 \%$ of their body fat each year. Their fat stores are still acting as nature intended. Under such circumstances energy-sparing adaptations serve a purpose and evolutionary pressures would presumably select people who are effective managers of their fat reserves, who can defend them metabolically when necessary, and who can lose and gain fat without harming their lean tissue. 
It is useful to bear this in mind throughout the remainder of the present paper. It indicates that, at least within certain limits, the human body is designed to gain and lose weight, and should be able to achieve either of these without long-term detriment. However, we should also be aware that profound obesity may be outside the design limits of the organism.

\section{ENERGY-SPARING ADAPTATIONS}

Physicians, dietitians and patients alike are interested in the following questions concerning alterations in metabolic rate and energy requirements: How large is the effect? What is the time-course? Do very-low-energy diets (VLED) exacerbate the reduction in metabolism? Can reductions in energy requirements be prevented? Is metabolic rate irreversibly depressed? Does adaptation explain apparent 'refractory obesity'?

\section{Time-course and magnitude of adaptations}

The first statement which can be made with some certainty is that a decrease in energy expenditure is a universal response to energy restriction except when purposely counteracted by other factors such as exercise or drugs. The adaptation is one of a series of survival strategies which come into play when the body detects a state of starvation. Fig. 1 illustrates the daily changes in basal metabolic rate (BMR) in three non-obese young men who were fed only $3.5 \mathrm{MJ} / \mathrm{d}$ whilst in a whole-body calorimeter for $13 \mathrm{~d}$ (Parkinson, 1990). BMR responded immediately and progressively. The decrease was proportionately greater than the decrease in body-weight: $15 \% v .4 \%$. It will become clear that this is a common finding.

Turning to the literature on slimming, Fig. 2 summarizes data from 515 subjects in twenty-nine published studies. The percentage suppression of resting metabolic rate (RMR) or of BMR $v$. duration of dieting is plotted. The slimming regimens varied considerably from VLED to only mild deficits. The differential effects of these will be examined later. It is important to note from Fig. 2 that almost all studies fall between a $5 \%$ and $25 \%$ suppression of RMR: a much smaller effect than many lay people would imagine.

Fig. 3(a) plots the suppression of RMR $v$. percentage weight loss in the subjects from Fig. 2 for whom it could be calculated. The response is quite consistent across studies and an exponential fit seems to plateau between -20 and $-25 \%$. In Fig. 3(b) the results of some underfeeding experiments in lean people have been added to see whether the extra fat mass of obese subjects reduces the extent to which RMR is suppressed. With the exception of the Minnesota semi-starvation study (Keys et al. 1950) there appears to be no discernible difference, but by the end of the Keys et al. (1950) study BMR was suppressed by $40 \%$ which is substantially greater than the changes observed in obese people even after massive weight loss.

Expression of all this RMR data relative to changes in fat-free mass (FFM) would show an average maximum change of about $-15 \%$; this includes the Keys et al. (1950) data.

More information about the time-course of this metabolic adaptation is provided by an elegant study from Wageningen (de Boer et al. 1986) summarized in Fig. 4. Daily energy 
(a) Subject 1601
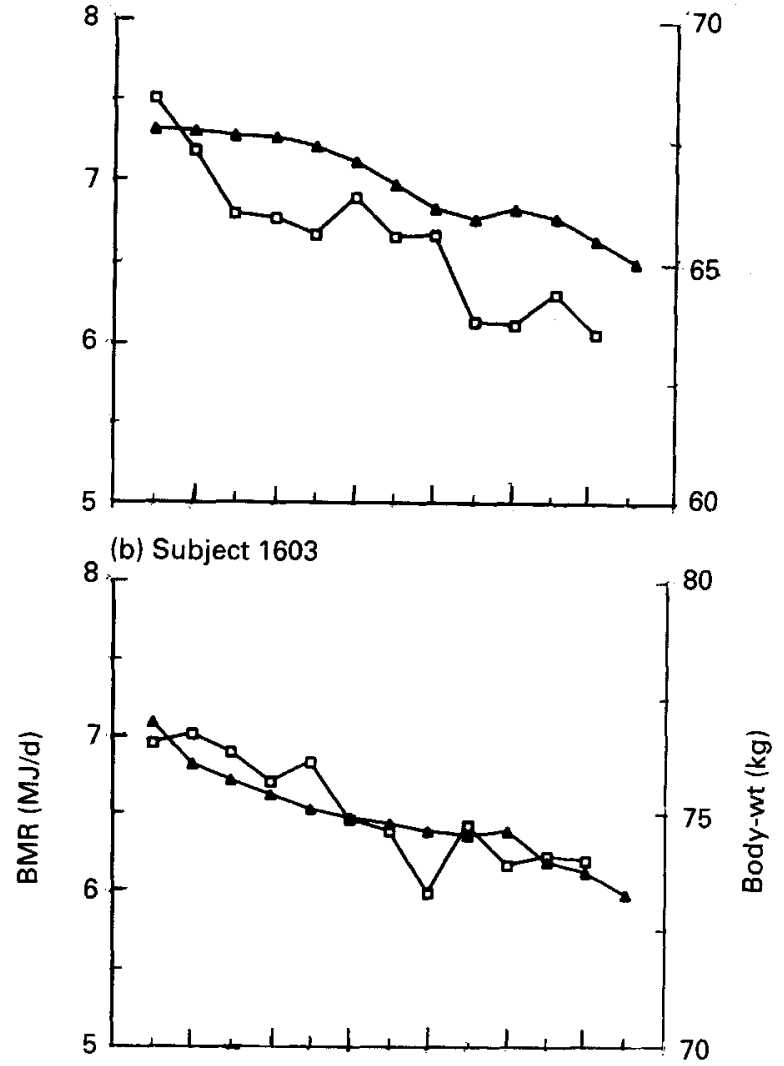

(c) Subject 1604

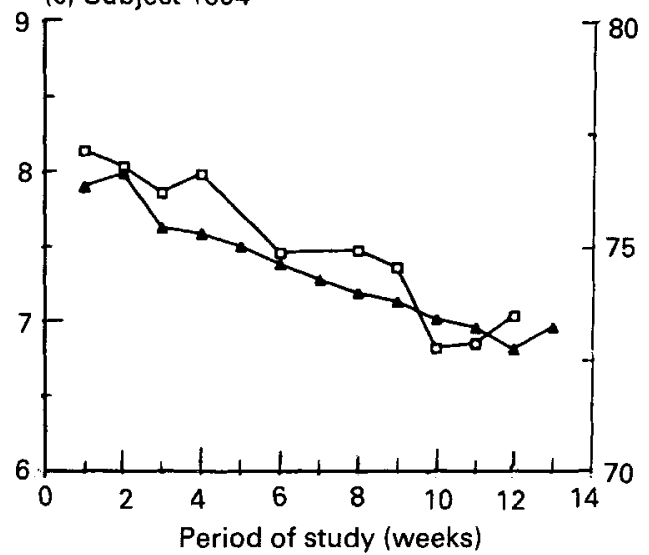

Fig. 1. Serial changes in body-weight ( $\mathbf{A})$ and basal metabolic rate (BMR) ( $\square$ ) in three non-obese men receiving 3.5 MJ/d in a whole-body calorimeter for $13 \mathrm{~d}$. Replotted from Parkinson (1990). 


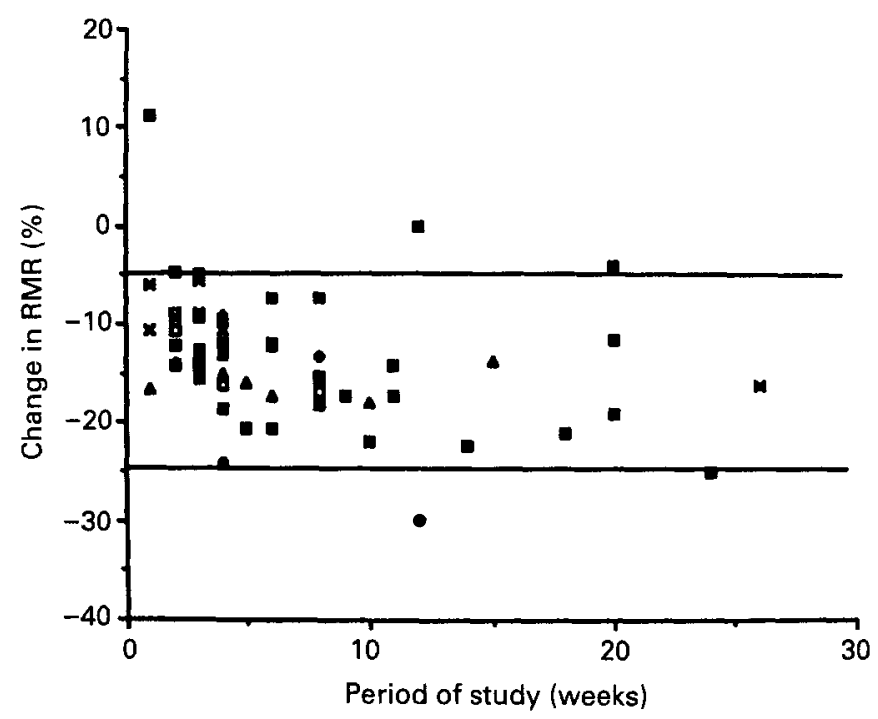

Fig. 2. Suppression of metabolic rate (basal metabolic rate or resting metabolic rate (RMR)) reported from 515 subjects (both sexes) in twenty-nine studies of weight loss employing a variety of diets and lasting from 1 to 26 weeks. Each point represents a group mean. Data from: Bray (1969); Apfelbaum et al. (1971); Rabast et al. (1981); Dore et al. (1982); Bessard et al. (1983); Webb \& Abrams (1983); Schutz et al. (1984); de Boer et al. (1986); Finer et al. (1986); Welle \& Campbell (1986); Barrows \& Snook (1987); Belko et al. (1987); Henson et al. (1987); Hill et al. (1987); Garby et al. (1988); Hendler \& Bonde (1988); Phinney et al. (1988); Poole \& Henson (1988); Alban Davies et al. (1989); Coxon et al. (1989); de Groot et al. (1989); Elliot et al. (1989); Garrow \& Webster (1989); Hainer et al. (1989); Heymsfield et al. (1989); Rattan et al. (1989); Foster et al. (1990); van Dale et al. $(1990 a, b)$.
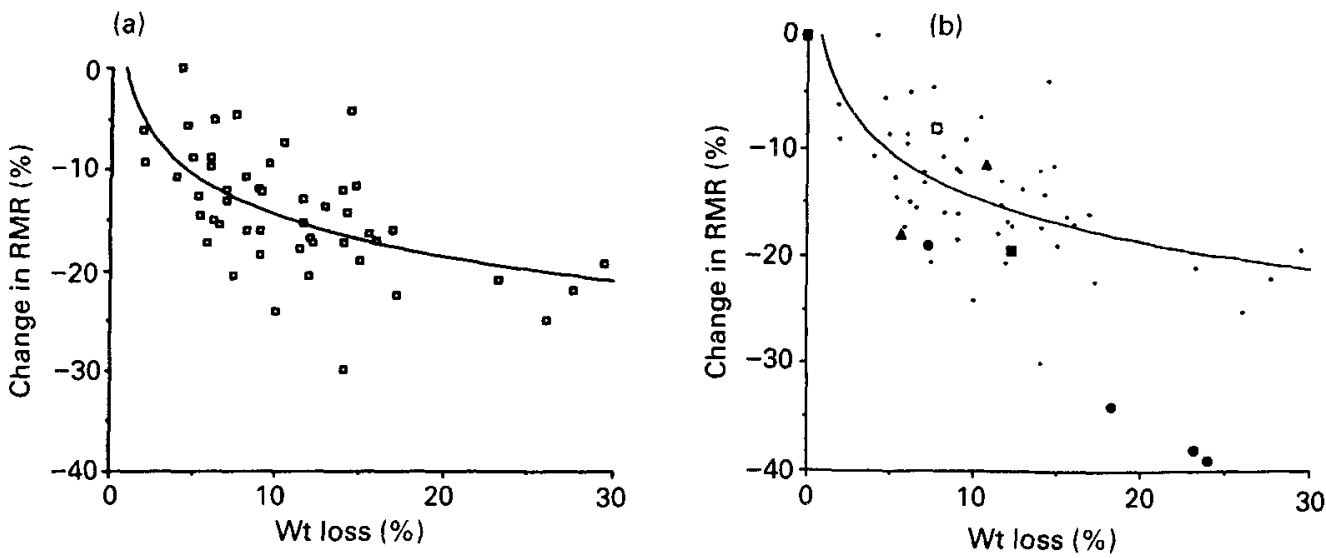

Fig. 3. (a) Suppression of metabolic rate (basal metabolic rate or resting metabolic rate (RMR)) $v$. percentage of initial weight lost for 439 subjects (both sexes) from twenty-eight studies. Values as for Fig. 2 but excluding studies in which percentage weight loss could not be calculated: Welle \& Campbell (1986); Coxon et al. (1989); Rattan et al. (1989). (b) Addition to (a) of data from four studies of experimental underfeeding in

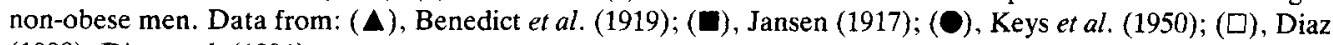
(1990); Diaz et al. (1991). 


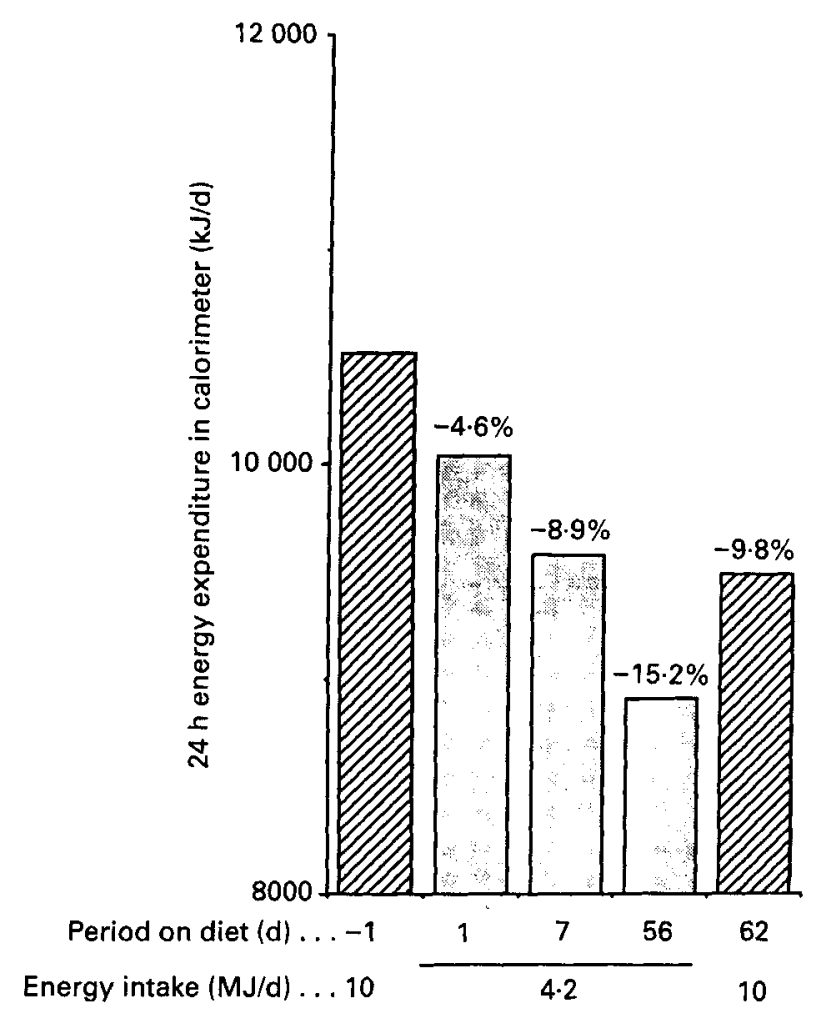

Fig. 4. Daily energy expenditure of fourteen overweight women receiving a $4 \cdot 2 \mathrm{MJ} / \mathrm{d}$ diet for 8 weeks. Replotted from de Boer et al. (1986).

expenditure was measured by whole-body calorimetry in fourteen overweight women who received a $4 \cdot 2 \mathrm{MJ} / \mathrm{d}$ diet for 8 weeks. Note that $24 \mathrm{~h}$ expenditure was decreased by almost $5 \%$ on the very first day of the diet, a fact previously reported by others (e.g. Dauncey, 1980) and well known to energy physiologists who make every attempt to maintain subjects in energy balance during calorimetry measurements in order to exclude confounding effects of diet. By the end of the 8-week diet period $24 \mathrm{~h}$ energy expenditure had decreased by $15 \%$, but on the first day of being refed a normal maintenance diet it increased again by about $6 \%$.

Thus, we can conclude that an important component of the adaptation is extremely labile and responds to changes in energy intake within $24 \mathrm{~h}$.

\section{VLED and metabolic adaptation}

We could find only one study which has made a direct comparison of a VLED $v$. less radical forms of dieting in order to test the question: Does rapid weight loss tend to invoke a greater protective suppression of BMR than gradual weight loss? This compared the effects of a regimen including a 7 -week period on a $2 \cdot 1 \mathrm{MJ} / \mathrm{d}(500 \mathrm{kcal} / \mathrm{d})$ VLED within a 24-week period on $5 \mathrm{MJ} / \mathrm{d}(1200 \mathrm{kcal} / \mathrm{d})$ against those of a 'balanced 


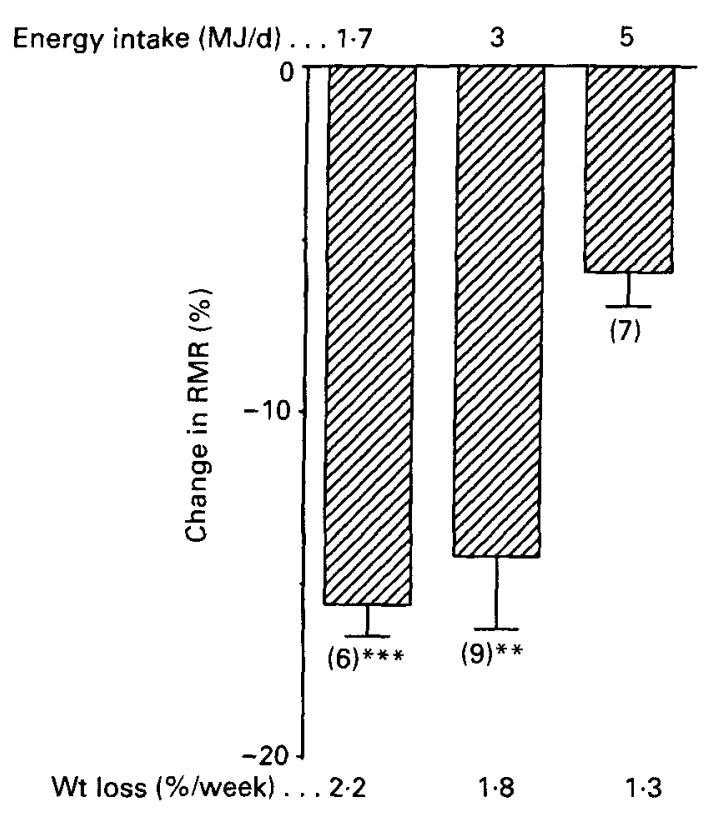

Fig. 5. Degree of suppression of resting metabolic rate (RMR) on diets providing different energy intakes. Results are from 4-6 weeks after commencement of diet. Values are means with their standard errors represented by vertical bars for no. of studies shown in parentheses. Mean values were significantly different from those for $5 \mathrm{MJ} / \mathrm{d} ;{ }^{* *} P<0 \cdot 01,{ }^{* * *} P<0 \cdot 001$. Data from: Bray (1969); Apfelbaum et al. (1971); Rabast $e$ t al. (1981); Dore et al. (1982); Bessard et al. (1983); Webb \& Abrams (1983); Schutz et al. (1984); de Boer et al. (1986); Finer et al. (1986); Welle \& Campbell (1986); Barrows \& Snook (1987); Belko et al. (1987); Henson et al. (1987); Hill et al. (1987); Garby et al. (1988); Hendler \& Bonde (1988); Phinney et al. (1988); Poole \& Henson (1988); Alban Davies et al. (1989); Coxon et al. (1989); de Groot et al. (1989); Elliot et al. (1989); Garrow \& Webster (1989); Hainer et al. (1989); Heymsfield et al. (1989); Rattan et al. (1989); Foster et al. (1990); van Dale et al. $(1990 a, b)$.

deficit diet' providing $5 \mathrm{MJ} / \mathrm{d}(1200 \mathrm{kcal} / \mathrm{d})$ throughout (Foster et al. 1990). Weight loss on the two regimens followed a different time-course, but after 24 weeks was rather similar: $-12 \cdot 1 \% v .-10 \cdot 6 \%$. However, in the group receiving the VLED resting energy expenditure (REE) decreased by a maximum of $17.9 \%$ at week 10 and at week 24 remained at $-11.3 \%$. There was no significant change in REE in the group receiving the $5 \mathrm{MJ}$ diet for the full 24 weeks.

Since no other studies have made direct comparisons we have attempted to answer the question by combining data from twenty-two different studies which have used a range of dieting regimens for a duration of 4-6 weeks. The result is summarized in Fig. 5 for diets providing $1.7 \mathrm{MJ}$ (or below), $3 \mathrm{MJ}$ or $5 \mathrm{MJ}$. As anticipated there is a clear relationship between the severity of the treatment and the rate of weight loss, but there is also a highly significant difference between the $15 \%$ suppression of RMR elicited by diets of less than $3 \mathrm{MJ} / \mathrm{d}$ and the $5 \%$ suppression on diets providing $5 \mathrm{MJ} / \mathrm{d}$. This analysis strongly suggests a threshold, at or about $5 \mathrm{MJ} / \mathrm{d}$, below which the perceived advantages of rapid weight loss may, in the longer term, be offset by a more pronounced physiological defence against weight loss. 


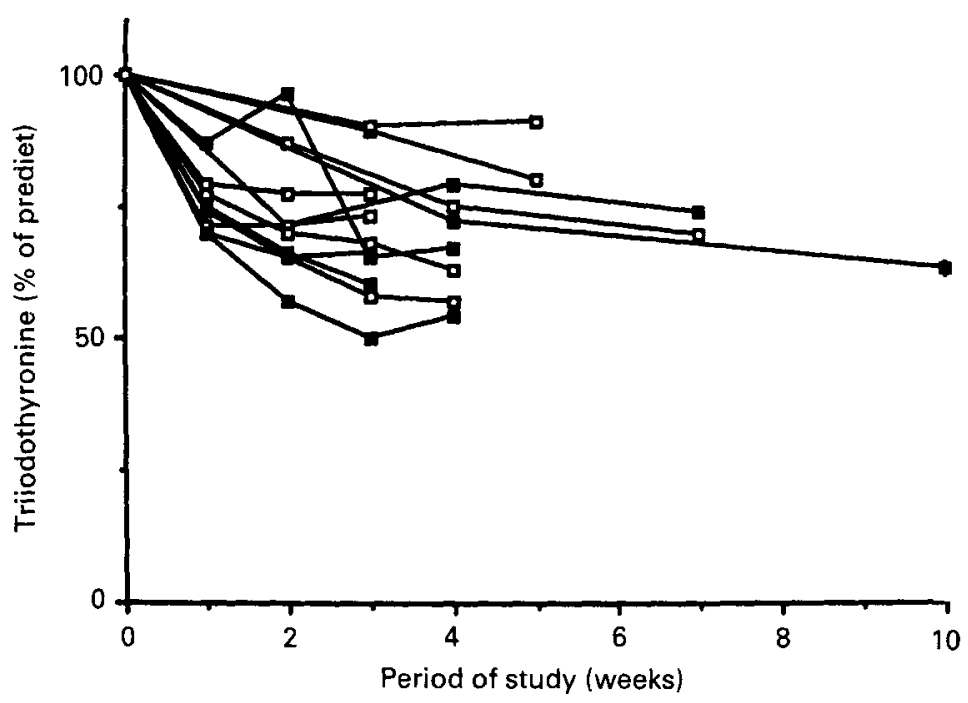

Fig. 6. Changes in triiodothyronine levels during dieting. Each point rcpresents a group mean value: ( $\mathbf{\sigma}$ ), Diets providing <2 MJ/d; ( $\square)$, diets providing 2-4 MJ/d. Data from: Krotkiewski et al. (1981); Rabast et al. (1981); Barrows \& Snook (1987); Hill et al. (1987); Hendler \& Bonde (1988); Phinney et al. (1988); Alban Davies et al. (1989).

\section{Prevention of the decrease in metabolic rate}

Pharmacological approaches. Fig. 6 shows the changes in triiodothyronine $\left(\mathrm{T}_{3}\right)$ levels observed in thirteen different experimental groups during dieting. It is clear that there is quite a profound decrease in circulating $\mathrm{T}_{3}$ levels down to about $70 \%$ of the prediet level and sometimes down as low as $50 \%$. The data have been divided once again according to the severity of the diet, but there seems to be no clear-cut difference at least below the level of $4 \mathrm{MJ} / \mathrm{d}$ which was the highest used in these studies. This could be because $T_{3}$ is as sensitive to carbohydrate intake as to energy. In those studies in which it was measured reverse $T_{3}$ was significantly raised indicating an altered conversion rate rather than altered release. Thyroxin $\left(\mathrm{T}_{4}\right)$ remains unchanged.

These changes in thyroid-hormone status play a key role in the suppression of metabolic rate, and this has led to considerable interest in the use of thyroid hormones as a treatment for obesity. The major problem with this approach is that, although it does successfully raise metabolic rate, administration of thyroid hormone invokes a concomitant and unacceptable increase in nitrogen excretion (Bray et al. 1973; Warwick \& Garrow, 1981; Koppeschaar et al. 1983). Indeed Osbourne et al. (1983) have proposed that the reduction in $T_{3}$ associated with severe energy restriction is an adaptive mechanism to conserve energy and to preserve lean body mass (LBM). The finding in obese dieters that the greater the reduction in $\mathrm{T}_{3}$ the greater is the preservation of LBM would support this hypothesis (Yang \& van Itallie, 1984).

More recently Welle \& Campbell (1986) have suggested that low-dose administration of $\mathrm{T}_{3}$ and $\mathrm{T}_{4}$, by maintaining the calorigenic hormones within physiological limits, might reverse the depression of RMR without inducing serious $\mathrm{N}$ loss. Their findings show that 
the change in RMR was not fully reversed by thyroid treatment, that $T_{3}$ levels were in fact raised above prediet levels and they provided no information on $\mathrm{N}$ losses. The future for this approach does not look promising.

A number of other pharmacological approaches have been tried over the years, but all have had unacceptable side-effects. More recently pharmaceutical companies are attempting to develop specific $\beta_{3}$-agonists intended to stimulate thermogenesis with a minimum of side-effects due to their highly specific receptor-binding characteristics. It is worth noting that the $\beta_{3}$-agonist actions of these compounds may be targeting metabolic reactions other than those which are being suppressed by dieting. Thus, rather than reversing the dieting effect, they may counteract it by stimulating alternative thermogenic processes.

Exercise. Perhaps the most thoroughly researched means of preventing the fall in BMR is through physical exercise. The potential advantages of exercise are numerous and include: increased energy use during the exercise itself and in the post-exercise period, stimulation of fat as opposed to carbohydrate oxidation, protection of lean body mass (see later), health benefits, and possible reversal of the diet-induced suppression of BMR.

Several studies have addressed the final point using protocols which include a direct comparison of groups treated with diet alone or with diet plus exercise. Some of these studies appear to show that exercise is very effective at protecting metabolic rate, notably those of van Dale $(1990 a, b)$ and of Mole et al. (1989). However, Fig. 7 summarizes the results from nine such studies, and demonstrates that, although a majority of studies suggest a positive effect, the case in favour of exercise is by no means overwhelming. Those studies which do find an effect usually conclude that the mechanism is partly a protection of FFM (see p. 454) and partly an elevation of metabolic activity per unit of existing tissue.

Advocates of exercise might claim that failure to demonstrate an effect results from a failure to obtain the necessary exercise compliance. The sceptics will respond by saying that it is the very difficulty of persuading obese people to take an effective amount of exercise which limits its efficacy.

\section{Post-dieting residual effects on metabolic rate}

A further important aspect of the dieting-induced reduction in metabolic rate relates to the energy requirements for maintaining people in a post-obese state. Is it true that energy expenditure is permanently depressed by dieting and to such an extent that successful slimmers have to maintain their energy intake down at exceptionally low levels in order to avoid the relapse towards obesity which is so common? In our own studies we have found very little evidence to support this claim.

First, we have observed the effects of yo-yo dieting or weight-cycling by following a group of overweight women through three consecutive periods of 2 weeks VLED followed by 4 weeks ad lib. feeding (Jebb et al. 1991). The results are summarized in Fig. 8 which clearly illustrates that the acute suppression of BMR during each diet period was reversed during the ad lib. intervals. After the full 18 weeks of the study body-weight had decreased by almost $6 \mathrm{~kg}$, but BMR was not significantly depressed. This refutes Cannon's theory popularized in his book Dieting Makes You Fat (Cannon \& Einzig, 1983). 


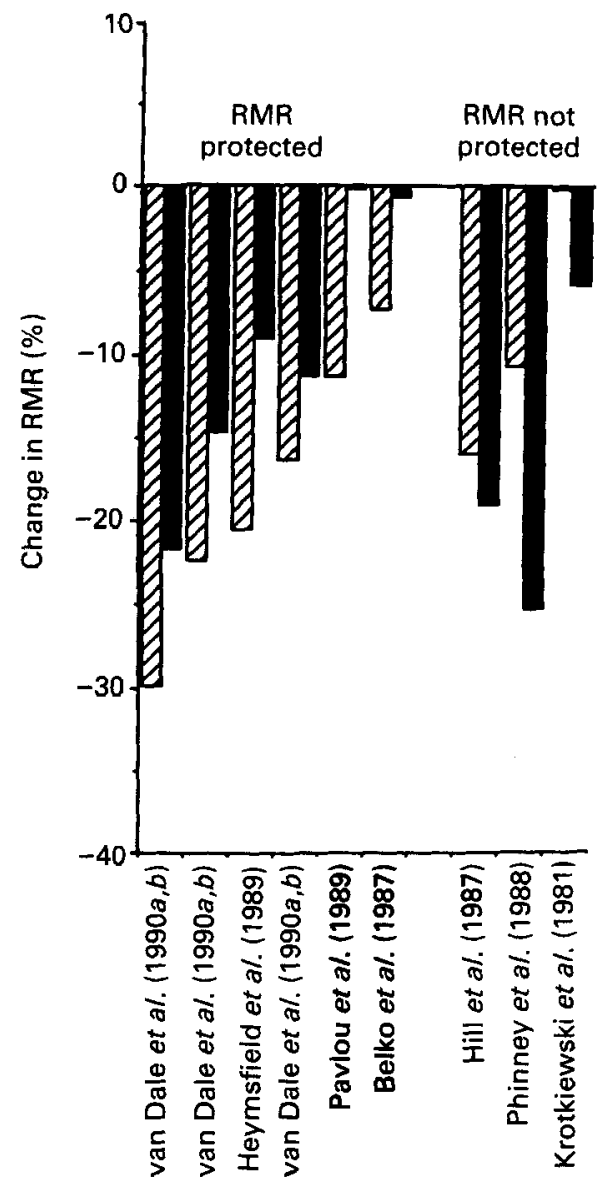

Fig. 7. A summary of published results investigating the effect of exercise in preventing diet-induced reductions in metabolic rate. (因), Diet alone; ( $\mathbf{0})$, diet plus exercise; RMR, resting metabolic rate.
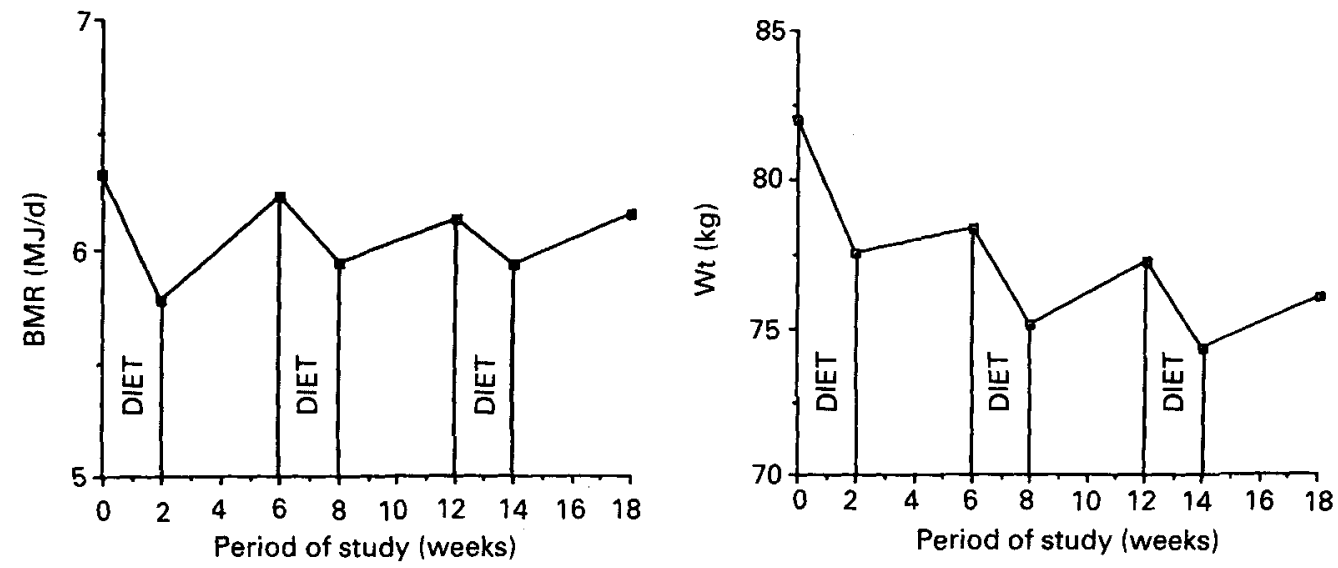

Fig. 8. The effect of experimentally induced 'yo-yo' dieting on basal metabolic rate (BMR) in eleven overweight women undergoing three cycles of 2 weeks on a very-low-energy diet followed by 4 weeks ad lib. eating. Data from Jebb et al. (1991). 
Second, we have found that the free-living energy requirements of a group of post-obese women were virtually identical to those of constitutionally lean controls when assessed by doubly-labelled water (Goldberg et al. 1991). Although the energy requirements of the post-obese were slightly depressed when expressed on a per $\mathrm{kg}$ basis they were on average slightly heavier than the never-obese group. This is always likely to be the case since very few successful slimmers attain their 'ideal body-weight', and in practice a body mass index of less than $25 \mathrm{~kg} / \mathrm{m}^{2}$, or a body-weight of less than $12 \%$ above ideal, is often taken as the target. Our measurements indicated that the post-obese group would not gain any weight on a daily intake of approximately $9 \cdot 3 \mathrm{MJ} / \mathrm{d}$. Geissler et al. (1987) and McNeill et al. (1990) have reported broadly similar findings.

Thus, claims that patients only have to 'look at a cream cake' to regain weight can safely be dismissed. It may be true that people do have an extraordinary propensity to regain weight after dieting, but it does not seem to be mediated through excessively low energy requirements. Other possible explanations exist. For instance, Kern et al. (1990) have shown that following VLED treatment the level of heparin-releasable lipoprotein lipase (EC 3.1.1.34) was doubled and the amount of lipoprotein lipase immunoreactive protein in adipose tissue was increased by a factor of four. Similarly, Kasim et al. (1986) have demonstrated that dieting can induce a $200 \%$ increase in lipoprotein lipaseactivator level. These changes would encourage the rapid sequestration of the lipid portion of meals and may encourage a rebound towards fatness, but they are quite independent of energy expenditure and any gain in body fat must ultimately be mediated through appetite and consumption in excess of expenditure.

\section{Practical consequences for slimmers of metabolic adaptations}

To what extent does the protective conservation of energy invoked by dieting really hinder an obese person's ability to lose weight?

We have already demonstrated that energy requirements are rarely reduced by more than $25 \%$ when expressed in absolute terms or $15 \%$ expressed on a body-weight or FFM basis. Also that, when dieting ceases, metabolic rate reverts to a level which is broadly appropriate for the new body size and composition.

These conclusions form the basis of a hypothetical calculation designed to illustrate the practical significance of energy-sparing adaptations. The predicted weight loss during a 12-week period on a VLED followed by a 12-week maintenance period has been calculated for a subject initially weighing $85 \mathrm{~kg}$ and having a daily energy expenditure of $10 \mathrm{MJ} / \mathrm{d}$. The results are summarized in Fig. 9 which shows the anticipated weight loss on diets providing 5, 3 and $1.7 \mathrm{MJ} / \mathrm{d}$. The calculations assumed pro rata decreases in energy expenditure with decreasing body-weight and an additional $5 \%$ adaptation on the $5 \mathrm{MJ}$ diet and 15\% adaptation for the other diets (see Fig. 5).

After 12 weeks the person's weight would be $73 \mathrm{~kg}$ on $5 \mathrm{MJ} / \mathrm{d}$ and $67 \mathrm{~kg}$ on $1.7 \mathrm{MJ} / \mathrm{d}$. After the maintenance period at $8 \mathrm{MJ} / \mathrm{d}$ this difference would have diminished to $70 \mathrm{~kg} v$. $67 \mathrm{~kg}$.

Fig. 9 shows the anticipated weight loss on the $1.7 \mathrm{MJ} / \mathrm{d}$ diet if no adaptation had occurred. Weight after 12 weeks would be just $3 \mathrm{~kg}$ lower and after a further 12 weeks this would have risen to $4 \mathrm{~kg}$. These differences are not very large and should not be exaggerated such that they discourage overweight people from tackling their obesity. 


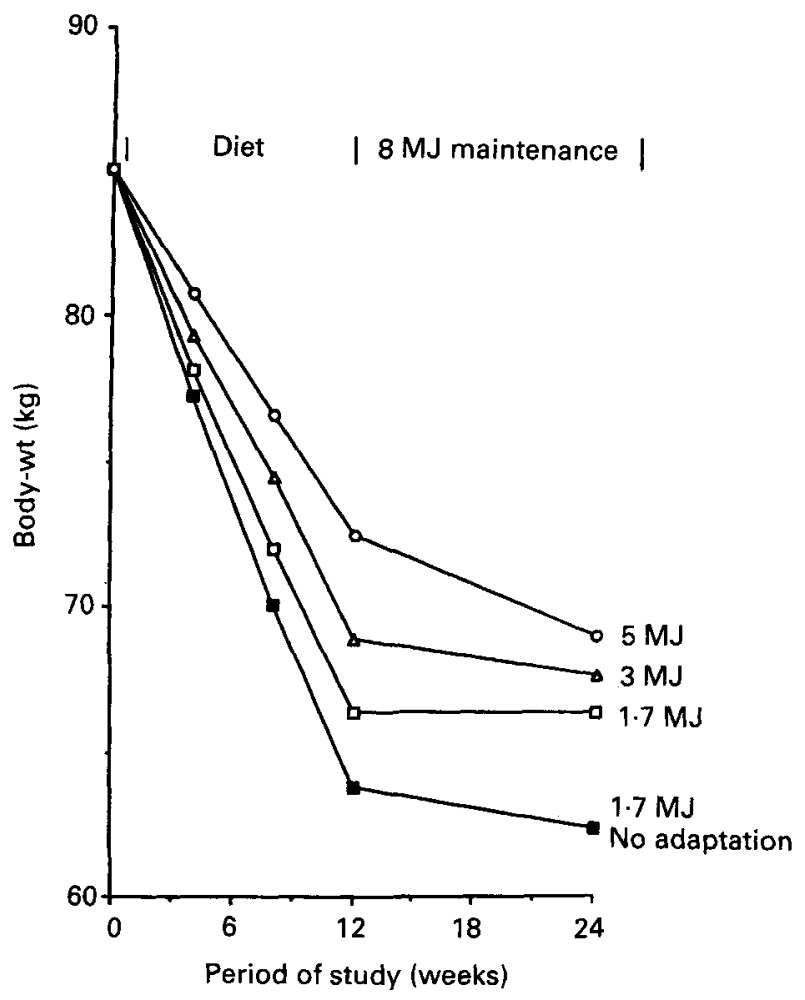

Fig. 9. A hypothetical calculation of anticipated rates of weight loss on a variety of diets with and without the existence of energy-sparing adaptations. Subject's initial weight assumed to be $85 \mathrm{~kg}$ and initial energy requirement assumed to be $10 \mathrm{MJ} / \mathrm{d}$. Energy requirements were adjusted pro rata for weight changes with an additional adaptive component of $-5 \%$ on $5 \mathrm{MJ} / \mathrm{d}$ and $-15 \%$ on 1.7 and $3 \mathrm{MJ} / \mathrm{d}$.

\section{Summary of conclusions regarding energy-sparing adaptations}

1. Physiological mechanisms do act to suppress metabolic rate whilst slimming.

2. BMR is only depressed by more than $20 \%$ after massive weight loss.

3. Diets providing less than $5 \mathrm{MJ} / \mathrm{d}$ seem to exacerbate the effect.

4. Exercise probably has a protective effect.

5. After dieting BMR returns to a level commensurate with the new body size.

6. Lay people have been unjustifiably discouraged by exaggerated reports of energysparing adaptations.

\section{THE COMPOSITION OF WEIGHT LOSS}

The primary questions in respect to the composition of the weight loss induced by dieting are: What determines the ratio fat:lean tissue loss? What is the optimal ratio? Do VLED cause excessive loss of lean tissue? Does exercise protect lean tissue? 


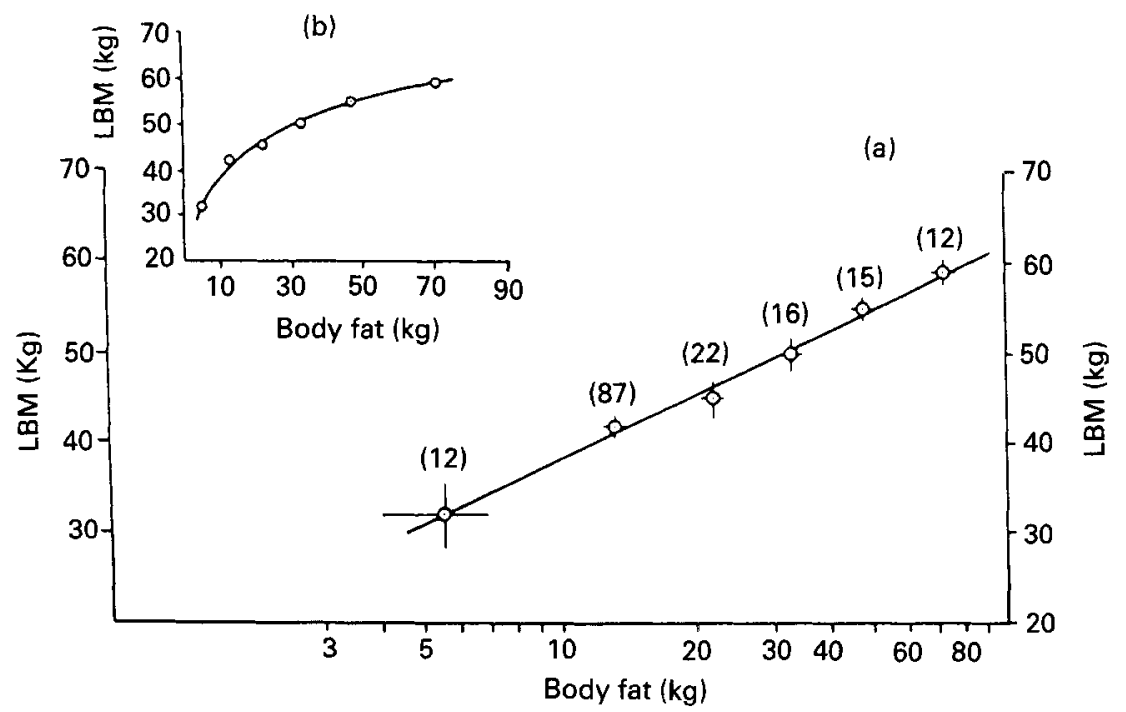

Fig. 10. (a) Plot of lean body mass (LBM; $\mathrm{kg})$ v. $\log _{10}$ body fat ( $\mathrm{kg}$ ) for females grouped according to body fat content. Values are means with 2 SEM, represented by error bars, for nos. of subjects shown in parentheses. (b) Plot of LBM $v$. body fat from the same data. Reproduced with permission, from Forbes (1987).

In answering the first three questions we have drawn extensively on the work of Forbes (1987) who has analysed body composition data from many of his own studies of women ranging from anorexics to the morbidly obese. His findings (Fig. 10) show that a plot of LBM $v$. body fat yields a well-behaved curvilinear relationship which becomes linear on $\log$ transformation. Examination of this curve shows that a thin person losing $10 \mathrm{~kg}$ fat would have to lose about $15 \mathrm{~kg}$ lean tissue if their body composition was to remain on this line representing (assumed) appropriate proportions of fat to LBM. Likewise a fat person losing $10 \mathrm{~kg}$ would only be expected to lose $2-3 \mathrm{~kg}$.

Fig. 11(a) shows that Forbes (1987) was able to find a considerable amount of experimental evidence in support of his contention that these relationships would hold in practice. The curve is the same as in Fig. 10 but re-expressed with the change in LBM:change in body-weight ( $\triangle \mathrm{LBM}: \triangle \mathrm{BW}$ ) on the $y$ axis. Thus, a value of 0.4 means that the composition of weight loss was $40 \%$ LBM and $60 \%$ fat. Once again if people maintain a relatively normal body composition as they lose weight their data would be expected to lie along this line. Forbes (1987) has plotted a number of group mean results from studies involving a total of 260 men and women dieting for at least 4 weeks. It is clear that those subjects who are on mild reducing diets (Fig. 11(a)) do lie close to his predictive line. It also appears that people on more-extreme diets lose a greater proportion of LBM than would be anticipated.

The importance of Fig. 11(a) in understanding what Forbes (1987) describes as 'the companionship of lean and fat tissue' and in determining the appropriate composition of weight loss is such that we tested its robustness by adding in all pertinent data published in the 3 years since Forbes, (1987) original paper and adhering to the same inclusion criteria. The updated version, shown in Fig. 11(b), provides a remarkable level of confirmation. As before, the subjects on mild reducing diets have values which tend to lie 
(a)

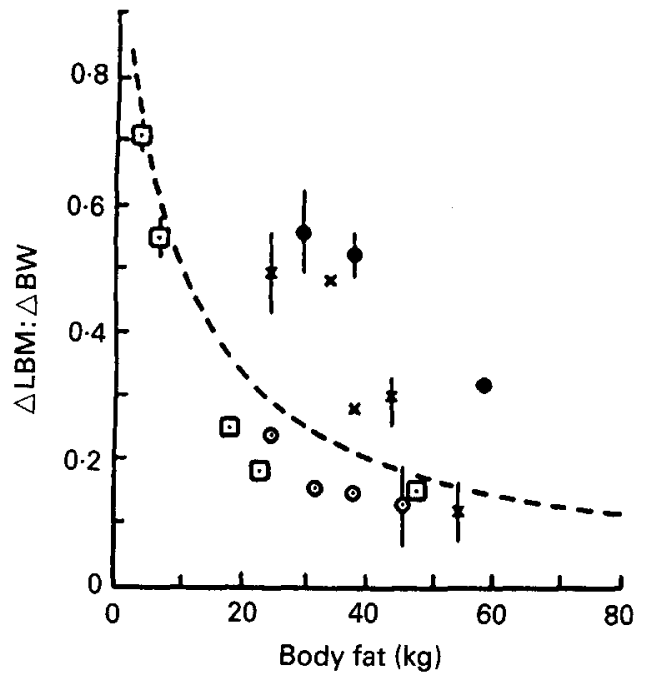

(b)

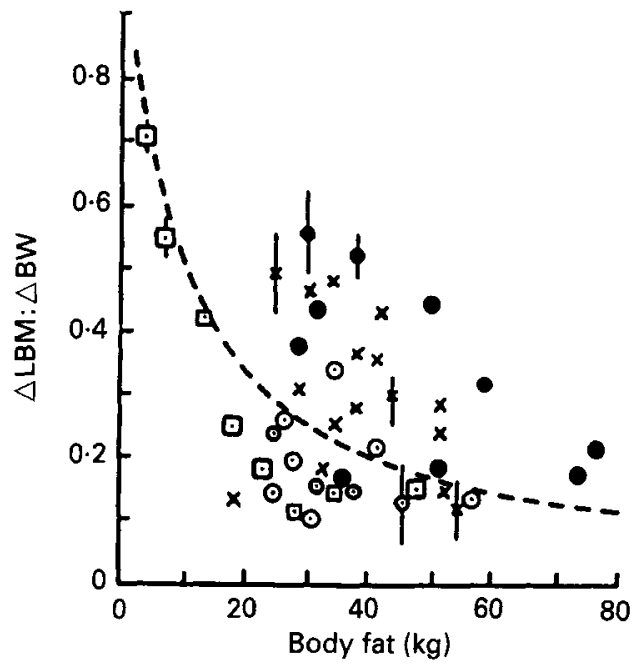

Fig. 11. Plots of relative weight loss ( $\triangle B W$ ) due to lean body mass (LBM) $(\triangle L B M: \triangle B W$ ) in underfeeding experiments of at least 4-week duration, with subjects grouped according to midpoint body fat content and by energy intake: (O), 0-1.8 MJ/d (0-440 kcal/d) $(n 25) ;(\mathrm{x}), 2 \cdot 1-3.8 \mathrm{MJ} / \mathrm{d}(500-900 \mathrm{kcal} / \mathrm{d})(n 77) ;(0), 4 \cdot 2-5 \cdot 9$ $\mathrm{MJ} / \mathrm{d}(1000-1400 \mathrm{kcal} / \mathrm{d})(n 81) ;(\square), 6 \cdot 3-7.9 \mathrm{MJ} / \mathrm{d}(1500-1900 \mathrm{kcal} / \mathrm{d})(n 80) ;(---)$ based on relationship derived in Fig. 10.

(a) Original plot ( $n$ 263) from Forbes (1987), reproduced with permission. (b) Updated version $(n$ 548) using Forbes' (1987) original inclusion criteria and the following sources: Barrows \& Snook (1987); Belko et al. (1987); Henson et al. (1987); Hill et al. (1987); Wirth et al. (1987); Ballor et al. (1988, 1990); Hendler \& Bonde (1988); Wadden et al. (1988); Alban Davies et al. (1989); Coxon et al. (1989); de Groot et al. (1989); Deurenberg et al. (1989); Elliot et al. (1989); Hammer et al. (1989); Heymsfield et al. (1989); Pavlou et al. (1989); Vansant et al. (1989); Foster et al. (1990); Saris \& van Dale (1990).

on or below the line, the more-extreme diets $(2 \cdot 1-3 \cdot 8 \mathrm{MJ} / \mathrm{d}(500-900 \mathrm{kcal} / \mathrm{d}))$ are intermediate, and the lowest-energy diets are well above the line, with one exception. This is an 18-week VLED study which only achieved a weight loss of a little in excess of $1 \% /$ week, indicating a considerable degree of non-compliance and suggesting that it should really be replotted as a 'more-extreme' diet or even 'mild reducing' diet.

Fig. 11 provides answers to three of the original four questions posed in this section. First, it tells us the composition of weight loss is primarily determined by two factors: the initial fatness of the subject and the severity of the reducing regimen. Second, it tells us that the optimal composition of weight loss, if the target is to re-establish a normal body composition, depends on initial fatness. An extremely obese person should have a $\triangle \mathrm{LBM}: \triangle \mathrm{BW}$ value of less than $0 \cdot 2$, whereas a lean person, if they were to slim, would have a much higher ratio. At the sorts of fat masses common in dieting women a ratio of about 0.25 would be appropriate, which agrees with Garrow's (1988) recommendation. Third, the graph suggests that the diets containing the least energy do appear to induce a greater than optimal loss of lean tissue.

Regarding this final point, Garrow et al. (1989) have recently published evidence of a greater loss of $\mathrm{N}$ on a VLED than on a $3.3 \mathrm{MJ} / \mathrm{d}(800 \mathrm{kcal} / \mathrm{d})$ milk diet based on a cross-over trial. There is in fact quite a substantial body of evidence based on $\mathrm{N}$-balance 
measurements, but it is open to a variety of interpretations for a number of reasons: the results tend to be confined to short periods of dieting due to the tedium of balance measurements for experimenter and subjects alike; there is a great deal of individual variation in the results; and it can be argued that the virtually obligatory confinement of subjects to a metabolic ward with its associated restriction of physical activity might encourage $\mathrm{N}$ loss, an effect which would not be present with most of the analyses of body composition changes presented previously since subjects were usually living at home between measurements.

\section{The effect of exercise in protecting lean body mass}

There have been a number of studies which have directly addressed the question of whether the incorporation of exercise into a slimming regimen has a protective effect on LBM. The published data are summarized in Fig. 12 in which the $y$ axis represents

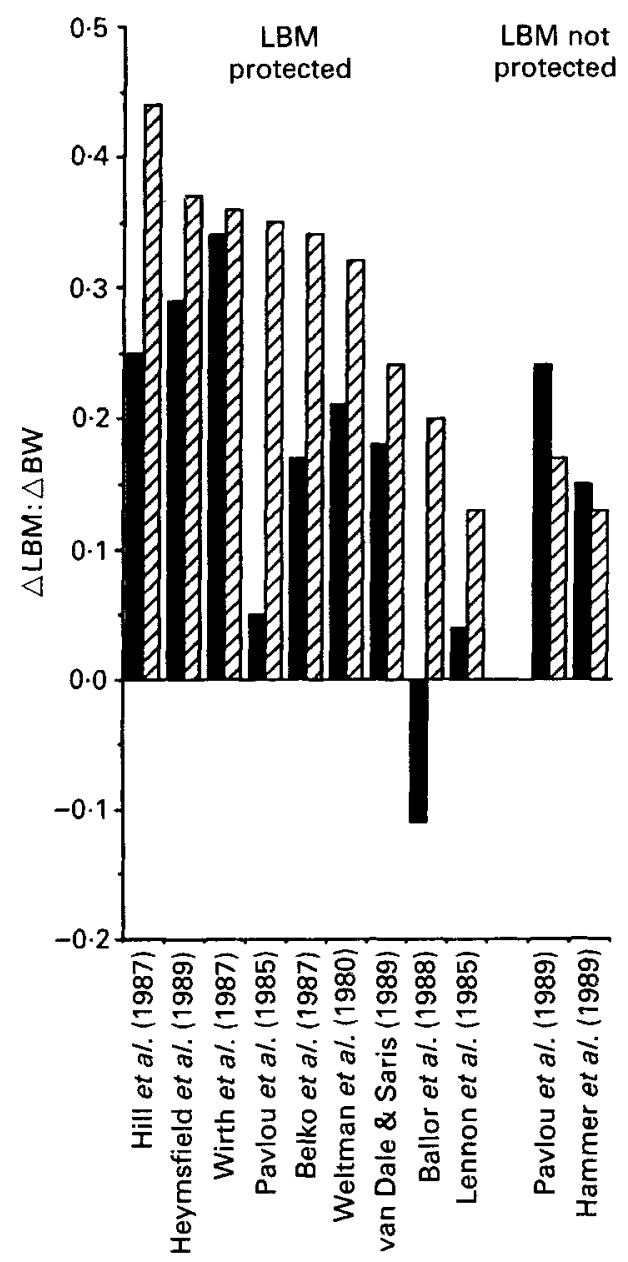

Fig. 12. A summary of published results investigating the effect of exercise in preventing loss of lean body mass (LBM). ( $\mathbb{Z})$, Diet alone; (ש), diet plus exercise. $\triangle \mathrm{LBM}: \triangle B W$, change in LBM relative to body-weight (BW) loss. 
$\triangle \mathrm{LBM}: \triangle \mathrm{BW}$ as before. If exercise protects $\mathrm{LBM}$ we would anticipate that values for diet plus exercise would be smaller than those for diet alone. This time the evidence in favour of exercise is somewhat stronger with nine studies showing a positive effect and only two showing negative effects, of which one was really a neutral result. Therefore, exercise does seem to be useful in protecting LBM if people can be persuaded to comply. Exercise may correct the apparent excess LBM loss which accompanies very rapid dieting, although definitive studies have not yet been published.

\section{Summary of conclusions regarding composition of weight loss}

1. Loss of some lean tissue during dieting is appropriate.

2. Forbes' (1987) analysis of the factors determining $\triangle \mathrm{LBM}: \triangle B W$ is confirmed by recent data.

3. Garrow's (1988) 25\% LBM:75\% fat loss 'rule-of-thumb' is also confirmed.

4. There is evidence that VLED cause a greater than optimal loss of lean tissue.

5. Exercise seems to be effective in protecting against excessive lean tissue loss.

\section{OVERALL CONCLUSIONS}

Self-protecting physiological responses to slimming are a very real phenomenon. However, many people have acquired an exaggerated impression about them and believe that the body's defence mechanisms are a virtually insurmountable barrier to successful weight loss. The present paper has illustrated that they are not so powerful as to be insurmountable. The sooner nutritionists remove this excuse from the range of demotivating myths concerning slimming the more likely we are to effect successful long-term treatment.

\section{REFERENCES}

Alban Davies, H. W., McLean Baird, I., Fowler, J., Mills, I. H., Ballie, J. E., Rattan, S. \& Howard, A. N. (1989). Metabolic responses to low- and very-low-calorie diets. American Journal of Clinical Nutrition 49, 745-751.

Apfelbaum, M., Bostsarron, J. \& Lacatis, D. (1971). Effect of caloric restriction and excessive caloric intake on energy expenditure. American Journal of Clinical Nutrition 24, 1405-1409.

Ballor, D. L., Katch, V. L., Becque, M. D. \& Marks, C. R. (1988). Resistance weight training during caloric restriction enhances lean body weight maintenance. American Journal of Clinical Nutrition 47, $19-25$.

Ballor, D. L., McCarthy, J. P. \& Wilterdink, E. J. (1990). Exercise intensity does not affect the composition of diet- and exercise-induced body mass loss. American Journal of Clinical Nutrition 51, 142-146.

Barrows, K. \& Snook, J. T. (1987). Effect of a high-protein, very-low-calorie diet on resting metabolism, thyroid hormones, and energy expenditure of obese middle-aged women. American Journal of Clinical Nutrition 45, 391-398.

Belko, A. Z., van Loan, M., Barbieri, T. F. \& Mayclin, P. (1987). Diet, exercise, weight loss, and energy expenditure in moderately overweight women. International Journal of Obesity 11, 93-104.

Benedict, F. G., Miles, W. R., Roth, P. \& Smith, H. M. (1919). Human Vitality and Efficiency Under Prolonged Restricted Diet. Washington, DC: Carnegie Institution of Washington.

Bessard, T., Schutz, Y. \& Jequier, E. (1983). Energy expenditure and postprandial thermogenesis in obese women before and after weight loss. American Journal of Clinical Nutrition 38, 680-693.

Bray, G. A. (1969). The effect of caloric restriction on energy expenditure in obese patients. Lancet ii, 397-398.

Bray, G. A., Melvin, K. E. W. \& Chopra, I. J. (1973). Effect of tryiodothyronine on some metabolic responses of obese patients. American Journal of Clinical Nutrition 26, 715-721. 
Cannon, G. \& Einzig, H. (1983). Dieting Makes You Fat. London: Century Publishing.

Coxon, A., Kreitzman, S., Brodie, D. \& Howard, A. (1989). Rapid weight loss and lean tissue: evidence for comparable body composition and metabolic rate in differing rates of weight loss. International Journal of Obesity 13, Suppl. 2, 179-181.

Dauncey, M. J. (1980). Metabolic effects of altering the $24 \mathrm{~h}$ energy intake in man using direct and indirect calorimetry, British Journal of Nutrition 43, 257-269.

de Boer, J. O., van Es, A. J. H., Roovers, L. C. A., van Raaij, J. M. A. \& Hautvast. J. G. A. J. (1986). Adaptation of energy metabolism of overweight women to low-energy intake, studied with whole-body calorimeters. American Journal of Clinical Nutrition 44, 585-595.

de Groot, L. C. P. G. M., van Es, A. J. H., van Raaij, J. M. A., Vogt, J. E. \& Hautvast, J. G. A. J. (1989). Adaptation of energy metabolism of overweight women to alternating and continuous low energy intake. American Journal of Clinical Nutrition 50, 1314-1323.

Deurenberg, P., Weststrate, J. A. \& Hautvast, J. G. A. J. (1989). Changes in fat-free mass during weight loss measured by bioelectrical impedance and by densitometry. American Journal of Clinical Nutrition 49, 33-36.

Diaz, E. O. (1990). Human energy balance. PhD Thesis, University of Cambridge.

Diaz, E., Prentice, A. M., Goldberg, G. R., Murgatroyd, P. R. \& Coward, W. A. (1991). Metabolic and behavioural responses to altered energy intake in man. 2. Experimental underfeeding. Proceedings of the Nutrition Society 50, 000-000.

Dore, C., Hesp, R., Wilkins, D. \& Garrow, J. S. (1982). Prediction of energy requirements in obese patients after massive weight loss. Human Nutrition: Clinical Nutrition 36C, 41-48.

Elliot, D. L., Goldberg, L., Kuehl, K. S. \& Bennett, W. M. (1989). Sustained depression of the resting metabolic rate after massive weight loss. American Journal of Clinical Nutrition 49, 93-96.

Finer, N., Swan, P. C. \& Mitchell, F. T. (1986). Metabolic rate after massive weight loss in human obesity. Clinical Science 70, 395-398.

Forbes, G. B. (1987). Lean body mass-body fat interrelationships in humans. Nutrition Reviews 45, 225-231.

Foster, G. D., Wadden, T. A., Feurer, I. D., Jennings, A. S., Stunkard, A. J., Crosby, L. O., Ship, J. \& Mullen, J. L. (1990). Controlled trial of the metabolic effects of a very-low-calorie diet: short- and long-term effects. American Journal of Clinical Nutrition 51, 167-172.

Garby, L., Kurzer, M. S., Lammert, O. \& Nielsen, E. (1988). Effect of 12 weeks light-moderate underfeeding on 24-hour energy expenditure in normal male and female subjects. European Journal of Clinical Nutrition 42, 295-300.

Garrow, J. S. (1988). Obesity and Related Diseases. Edinburgh: Churchill Livingstone.

Garrow, J. S. \& Webster, J. D. (1989). Effects on weight and metabolic rate of obese women of a $3.4 \mathrm{MJ}$ (800 kcal) diet. Lancet ii, 1429-1431.

Garrow, J. S., Webster, J. D., Pearson, M., Pacy, P. J. \& Harpin, G. (1989). Inpatient-outpatient randomised comparison of Cambridge diet versus milk diet in 17 obese women over 24 weeks. International Journal of Obesity 13, 521-529.

Geissler, C. A., Miller, D. S. \& Shah, M. (1987). The daily metabolic rate of the post-obese and the lean. American Journal of Clinical Nutrition 45, 914-920.

Goldberg, G. R., Black, A. E., Prentice, A. M. \& Coward, W. A. (1991). No evidence of lower energy expenditure in post-obese women. Proceedings of the Nutrition Society 50,109A.

Hainer, V., Kunesova, M., Stich, V., Parizkova, J., Zak, A., Wernischova, V., Kozich, V., Hrabak, P. \& Dedicova, L. (1989). Very low energy formula in the treatment of obesity. International Journal of Obesity 13, Suppl. 2, 185-188.

Hammer, R. L., Barrier, C. A., Roundy, E. S., Bradford, J. M. \& Fisher, A. G. (1989). Calorie-restricted low-fat diet and exercise in obese women. American Journal of Clinical Nutrition 49, 77-85:

Hendler, R. \& Bonde, A. A. (1988). Very-low-calorie diets with high and low protein content: impact on triiodothyronine, energy expenditure, and nitrogen balance. American Journal of Clinical Nutrition 48, 1239-1247.

Henson, L. C., Poole, D. C., Donahoe, C. P. \& Herber, D. (1987). Effects of exercisentraining on resting energy expenditure during caloric restriction. American Journal of Clinical Nutpition 46, 893-899.

Heymsfield, S. B., Casper, K., Hearn, J. \& Guy, D. (1989). Rate of weight loss during underfeeding:relation to level of physical activity. Metabolism 38, 215-223.

Hill, J. O., Sparling, P. B., Shields, T. W. \& Heller, P. A. (1987). Effects of exercise and food restriction on body composition and metabolic rate in obese women. American Journal of Clinical Nutrition 46, 622-630. 
Jansen, W. H. (1917). Untersuchungen uber Stickstoffbilanz bei kalorienarmer Ernahrung. Deutsches Archiv für klinische Medizin 124, 1-37.

Jebb, S. A., Goldberg, G. R., Coward, W. A., Murgatroyd, P. R. \& Prenicice, A. M. (1991). Effects of intermittent dieting on metabolic rate and body composition in obese women. International Journal of Obesity 15, 367-374.

Kasim, S., Maxwell, M. M., Dornfield, L., Schroth, P. \& Sowers, J. R. (1986). The effects of marked caloric restriction on lipoprotein lipase-activators in obese subjects. Nutrition Research 6, 773-783.

Kern, P. A., Ong, J. M., Saffari, B. \& Carty, J. (1990). The effects of weight loss on the activity and expression of adipose-tissue lipoprotein lipase in very obese humans. New England Journal of Medicine 322, 1053-1059.

Keys, A., Brozek, J., Henschel, A., Mickelsen, O. \& Taylor, H. L. (1950). The Biology of Human Starvation. Minneapolis, MN: University of Minnesota Press.

Koppeschaar, H. P. F., Meinders, A. E. \& Schwarz, F. (1983). Metabolic responses in grossly obese subjects treated with a very-low-calorie diet with and without triiodothyronine treatment. International Journal of Obesity 7, 133-141.

Krotkiewski, M., Toss, L., Bjorntorp, P. \& Holm, G. (1981). The effect of a very-low-calorie diet with and without chronic exercise on thyroid and sex hormones, plasma proteins, oxygen uptake, insulin and $\mathrm{C}$ peptide concentrations in obese women. International Journal of Obesity 5, 287-293.

Lennon, D., Nagle, F., Stratman, F., Shrago, E. \& Dennis, S. (1985). Diet and exercise training effects on resting metabolic rate. International Journal of Obesity $9,39-47$

McNeill, G., Bukkens, S. G. F., Morrison, D. C. \& Smith, J. S. (1990). Energy intake and energy expenditure in post-obese women and weight-matched controls. Proceedings of the Nutrition Society 49, 14A.

Mole, P. A., Stern, J. S., Schultz, C. L., Bernauer, E. M. \& Holcomb, B. J. (1989). Exercise reverses depressed metabolic rate produced by severe caloric restriction. Medicine and Science in Sports and Exercise 21, 29-33.

Osbourne, R. C., Myers, E. A., Rodbard, D., Burman, K. D., Georges, L. P. \& O'Brian, T. (1983). Adaptation to hypocaloric feeding: physiologic significance of the fall in serum $T_{3}$ as measured by pulse wave arrival time (QKd). Metabolism 32, 9-13.

Parkinson, S. A. (1990). In vivo measurements of changes in body composition. PhD Thesis, University of Cambridge.

Pavlou, K. N., Krey, S. \& Steffee, W. P. (1989). Exercise as an adjunct to weight loss and maintenance in moderately obese subjects. American Journal of Clinical Nutrition 39, 1115-1123.

Pavlou, K. N., Steffee, W. P., Lerman, R. H. \& Burrows, B. A. (1985). Effects of dieting and exercise on lean body mass, oxygen uptake, and strength. Medicine and Science in Sports and Exercise 17, 466-471.

Phinney, S. D., LaGrange, B. M., O'Connell, M. \& Danforth, E. (1988). Effects of aerobic exercise on energy expenditure and nitrogen balance during very low calorie dieting. Metabolism 37, 758-765.

Poole, D. C. \& Henson, L. C. (1988). Effect of acute caloric restriction on work efficiency. American Journal of Clinical Nutrition 47, 15-18.

Prentice, A. M., Whitehead, R. G., Roberts, S. B. \& Paul, A. A. (1981). Long-term energy balance in child-bearing Gambian women. American Journal of Clinical Nutrition 34, 2790-2799.

Rabast, U., Hahn, A., Reiners, C. \& Ehl, M. (1981). Thyroid hormone changes in obese subjects during fasting and a very-low-calorie diet. International Journal of Obesity 5, 305-311.

Rattan, S., Coxon, A., Kreitzman, S. \& Lemons, A. (1989). Maintenance of weight loss with recovery of resting metabolic rate following 8 weeks of very low calorie dieting. International Journal of Obesity 13, Suppl. 2, 189-192.

Saris, W. H. M. \& van Dale, D. (1989). Effects of exercise during VLCD diet on metabolic rate, body composition and aerobic power: pooled data of four studies. International Journal of Obesity 13, Suppl. 2, $169-170$.

Schutz, Y., Golay, A., Felber, J.-P. \& Jequier, E. (1984). Decreased glucose-induced thermogenesis after weight loss in obese subjects: a predisposing factor for relapse of obesity? American Journal of Clinical Nutrition 39, 380-387.

van Dale, D., Beckers, E., Schoffelen, P. F. M., ten Hoor, F. \& Saris, W. H. M. (1990a). Changes in sleeping metabolic rate and glucose induced thermogenesis during a diet or a diet/exercise treatment. Nutrition Research 10, 615-626.

van Dale, D. \& Saris, W. H. M. (1989). Repetitive weight loss and weight regain: effects on weight reduction, resting metabolic rate, and lipolytic activity before and after exercise and/or diet treatment. American Journal of Clinical Nutrition 49, 409-416. 
van Dale, D., Saris, W. H. M. \& ten Hoor, F. (1990b). Weight maintenance and resting metabolic rate 18-40 months after a diet/exercise treatment. International Journal of Obesity 14, 347-359.

Vansant, G., van Gaal, L., van Acker, K. \& de Leeuw, I. (1989). Short and long term effects of a very low calorie diet on resting metabolic rate and body composition. International Journal of Obesity 13, Suppl. 2, $87-89$.

Wadden, T. A., Stunkard, A. J., Johnston, F. E., Wang, J., Pierson, R. N., van Itallie, T. B., Costello, E. \& Pena, M. (1988). Body fat deposition in adult women. II. Changes in fat distribution accompanying weight reduction. American Journal of Clinical Nutrition 47, 229-234.

Warwick, P. M. \& Garrow, J. S. (1981). The effect of addition of exercise to a regime of dietary restriction on weight loss, nitrogen balance, resting metabolic rate and spontaneous physical activity in three obese women in a metabolic ward. International Journal of Obesity 5, 25-32.

Webb, P. \& Abrams, T. (1983). Loss of fat stores and reduction in sedentary energy expenditure from undereating. Human Nutrition: Clinical Nutrition 37C, 271-282.

Welle, S. L. \& Campbell, R. G. (1986). Decrease in resting metabolic rate during rapid weight loss is reversed by low dose thyroid hormone treatment. Metabolism 35, 289-291.

Weltman, A., Matter, S. \& Stamford, B. A. (1980). Caloric restriction and/or mild exercise: effects on serum lipids and body composition. American Journal of Clinical Nutrition 33, 1002-1009.

Wirth, A., Vogel, A. \& Schomig, G. (1987). Metabolic effects and body fat mass changes in obese subjects on a very-low-calorie diet with and without intensive physical training. Annals of Nutrition and Metabolism 31, 378-386.

Yang, M. U. \& van Itallie, T. B. (1984). Variability in body protein loss during protracted severe caloric restriction: role of triiodothyronine and other possible determinants. American Journal of Clinical Nutrition $40,611-622$. 